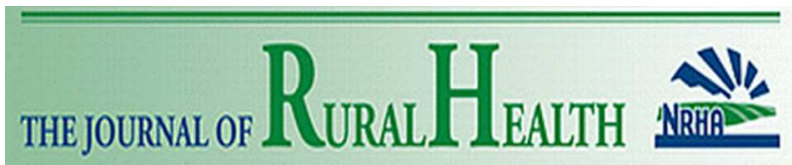

\title{
Medicaid Expansion under the Affordable Care Act and Insurance Coverage in Rural and Urban Areas
}

\begin{tabular}{|c|c|}
\hline Journal: & The Journal of Rural Health \\
\hline Manuscript ID & JRH-2016-08-0263.R1 \\
\hline Wiley - Manuscript type: & Original Article \\
\hline Keywords: & rural, Affordable Care Act, Medicaid, insurance \\
\hline Abstract: & $\begin{array}{l}\text { Purpose: To analyze the differential rural-urban impacts of the Affordable } \\
\text { Care Act Medicaid expansion on low-income childless adults' health } \\
\text { insurance coverage. } \\
\text { Methods: Using data from the American Community Survey years } 2011- \\
2015, \text { we conducted a difference-in-differences regression analysis to test } \\
\text { for changes in the probability of low-income childless adults having } \\
\text { insurance in states that expanded Medicaid versus states that did not } \\
\text { expand, after versus before the expansion, in rural versus urban areas. } \\
\text { Analyses employed survey weights, adjusted for covariates, and included a } \\
\text { set of falsification tests as well as sensitivity analyses. } \\
\text { Findings: Medicaid expansion under the Affordable Care Act increased the } \\
\text { probability of Medicaid coverage for targeted populations in rural and urban } \\
\text { areas, with a significantly greater increase in rural areas ( } p<.05 \text { ), but some } \\
\text { of these gains were offset by reductions in individual purchased insurance } \\
\text { among rural populations (p<.01). Falsification tests showed that the } \\
\text { insurance increases were specific to low-income childless adults, as } \\
\text { expected, and were largely insignificant for other populations. } \\
\text { Conclusions: The Medicaid expansion increased the probability of having } \\
\text { "any insurance" for the pooled urban and rural low-income populations, } \\
\text { and specifically increased Medicaid coverage more in rural versus urban } \\
\text { populations. There was some evidence that the expansion was } \\
\text { accompanied by some shifting from individual purchased insurance to } \\
\text { Medicaid in rural areas, and there is a need for future work to understand } \\
\text { the implications of this shift on expenditures, access to care and utilization. }\end{array}$ \\
\hline
\end{tabular}




\begin{abstract}
Purpose: To analyze the differential rural-urban impacts of the Affordable Care Act Medicaid expansion on low-income childless adults' health insurance coverage.

Methods: Using data from the American Community Survey years 2011-2015, we conducted a difference-in-differences regression analysis to test for changes in the probability of lowincome childless adults having insurance in states that expanded Medicaid versus states that did not expand, after versus before the expansion, in rural versus urban areas. Analyses employed survey weights, adjusted for covariates, and included a set of falsification tests as well as sensitivity analyses.

Findings: Medicaid expansion under the Affordable Care Act increased the probability of Medicaid coverage for targeted populations in rural and urban areas, with a significantly greater increase in rural areas $(\mathrm{p}<.05)$, but some of these gains were offset by reductions in individual purchased insurance among rural populations $(\mathrm{p}<.01)$. Falsification tests showed that the insurance increases were specific to low-income childless adults, as expected, and were largely insignificant for other populations.

Conclusions: The Medicaid expansion increased the probability of having "any insurance" for the pooled urban and rural low-income populations, and specifically increased Medicaid coverage more in rural versus urban populations. There was some evidence that the expansion was accompanied by some shifting from individual purchased insurance to Medicaid in rural areas, and there is a need for future work to understand the implications of this shift on expenditures, access to care and utilization.
\end{abstract}

Key words: rural; Affordable Care Act; Medicaid; insurance 


\section{Introduction}

The Patient Protection and Affordable Care Act (ACA) began in 2010, with several key provisions taking effect at later dates. One of those provisions, initiated in 2014, was the expansion of Medicaid by broadening coverage to low-income persons below $133 \%$ of the federal poverty level (FPL). States had the option to participate in the expansion, and at the time of this writing, 31 states and the District of Columbia had expanded, and 19 had not. ${ }^{1}$ Prior to the ACA, the FPL threshold varied by state and in most states, Medicaid eligibility was limited to low-income children, parents, pregnant women, and disabled people. After the ACA, Medicaid eligibility widened in expansion states, especially for childless adults who previously had little access to public insurance.

Past literature on the ACA Medicaid expansion demonstrated that the expansion resulted in overall decreases in uninsurance rates, increased access to care, and improved self-rated health. ${ }^{2-6,7}$ These short-term evaluations also reported that Medicaid expansion to childless adults, specifically, was associated with improved insurance rates and access to care measures for this vulnerable population. However, these past studies did not examine ACA effects separately for rural and urban areas.

There are reasons to believe that rural populations may particularly benefit from Medicaid expansion. Rural residents, for example, have higher uninsurance rates and face greater financial burdens from out-of-pocket healthcare costs. ${ }^{8-10}$ Thus, rural people may be more likely to respond to public health insurance expansions as a way to reduce their financial burden. Also, rural populations on average have lower incomes than their urban counterparts. ${ }^{11}$ Rural populations are therefore less likely to be able to afford individual-purchased private insurance (see Table 1), and so opportunities to gain access to insurance through Medicaid expansion may 
be particularly important for rural people. For these reasons (lower incomes, higher uninsurance rates, less availability of private alternatives), we would expect rural populations to differentially benefit from Medicaid expansion.

Nevertheless, there is limited information to date on the causal impacts of the Medicaid expansion for rural populations. A report by Karpman et al. ${ }^{12}$ does document changes in insurance rates after the Medicaid expansion separately for rural versus urban areas. However, these studies are descriptive in nature and do not examine whether differential changes for rural and urban populations were statistically meaningful, as this current paper does.

There is a large literature that studies the impact of public insurance expansions on rural insurance rates in alternate policy settings. For example, another key feature of the ACA was the introduction of Health Insurance Marketplaces (HIMs), which provide a means for enrollment into private insurance and subsidize premiums for people up to $400 \%$ FPL. Studies have reported that enrollment into HIMs has been lower in rural areas compared to urban, suggesting that rural populations are less able to take advantage of subsidized private insurance. ${ }^{13,14}$ A study by Look et al. ${ }^{15}$ analyzed the dependent coverage mandate, another ACA component that allows young adults to stay on their parents' employer sponsored insurance plans until age 26. Although Look et al. found that the improved insurance rates among young adults were not statistically different for rural versus urban areas, there is reason to expect that low-income populations (which the Medicaid expansion targets) may behave differently from the young adult population.

Additionally, there are a number of state-specific analyses of public insurance expansions undertaken, in some cases, prior to the full implementation of the ACA. Investigations in California, ${ }^{16}$ Kentucky, ${ }^{17}$ Wisconsin ${ }^{18}$ and Massachusetts ${ }^{19}$ each indicated that the expansions improved insurance coverage rates but did not report specific analyses of rural and urban 
differences. The Wisconsin study found that public insurance enrollment led to increased outpatient and inpatient visits among low-income adults in rural areas, but due to the nature of the data the study was unable to compare corresponding effects for urban areas.

Overall, there have been few studies to date which have analyzed the statistical significance of the Medicaid expansion's differential effects on rural versus urban populations. This paper contributes to the literature in three main ways. First, our model allows us to not only estimate the causal impact of Medicaid expansion on the probability of low-income childless adults having insurance, but also assess whether the differential effect on rural versus urban populations was statistically meaningful. Second, we utilize federal survey data with a large sample size and detailed information on source of insurance coverage, allowing for more robust analysis than that possible in the current ACA rural health literature. Third, we conduct a thorough set of sensitivity analyses and robustness checks which help validate our results.

\section{Methods}

Data. We used data from the American Community Survey (ACS), the largest household survey of its kind in the US. ${ }^{20}$ The ACS data consists of repeated cross sections of about 3 million individuals per year. Our data span the period January 2011 to December 2015. We start with the year 2011 because other ACA provisions went into effect in 2010 (such as the dependent coverage mandate) and may confound our results. There are several advantages of the ACS: First, its large sample size includes about one percent of the entire US population, and it is conducted by the US Census Bureau, which results in high response rates. Second, the survey is designed to be nationally representative as well as representative of each of the states. Third, it collects a wide range of information including detailed health insurance coverage, income, 
family size, and other socio-economic and demographic data. The ACS also contains state and Public Use Microdata Area (PUMA) geographic identifiers in its public-use version. ${ }^{21}$ These features allow us to document changes in insurance rates and source of coverage over time, as well as obtain precise estimates, even for subpopulations such as rural/urban within expansion and non-expansion states. The ACS has been used previously in studies of the ACA, including Courtemanche et al., ${ }^{4}$ Frean et al. ${ }^{3}$ and Buchmueller et al. ${ }^{22}$ (However, none of these studies specifically examined rural-urban heterogeneity.)

Measures. We defined an expansion indicator which equals 1 if the state enacted ACA Medicaid expansion as of June 2015, or 0 otherwise. All 50 states and DC are included in our analysis. Expansion states are: AR, AZ, CA, CO, CT, DC, DE, HI, IA, IL, IN, KY, MA, MD, MI, MN, NV, NH, NJ, NM, NY, ND, OH, OR, PA, RI, VT, WA, WI, and WV. (Although Wisconsin was not an ACA expansion state, the state received federal approval to offer Medicaid to childless adults below $100 \%$ FPL through the BadgerCare program. ${ }^{23}$ ) Non-expansion states are: AK, AL, FL, GA, ID, KS, LA, ME, MO, MS, MT, NC, NE, OK, SC, SD, TN, TX, UT, VA, and WY.

Of the 30 states and DC that are participating in the Medicaid expansion, nearly all states enacted their expansion in January 2014 except for the following: Alaska (September 2015), Indiana (February 2015), Louisiana (July 2016), Michigan (April 2014), Montana (January 2016), New Hampshire (August 2014), and Pennsylvania (January 2015). Since our data are at an annual frequency and go through 2015, we identified states that expanded after January 2014 as expansion states only for the years in which their expansion was effective at least half the year. Michigan, which expanded in the first half of 2014, was identified as expansion for the entire period. New Hampshire (which expanded in the second half of 2014) and Pennsylvania 
and Indiana (which expanded in the first half of 2015) were identified as expansion states only in 2015. Alaska (which expanded in the second half of 2015) and Montana and Louisiana (which expanded in 2016) are in the non-expansion group, since our data only go through 2015.

Although some states expanded Medicaid to low-income childless adults even before 2014 , most of these expansions were limited in terms of eligibility as well as coverage of services. For example, New Jersey elected to enact its ACA expansion in 2011 but extended Medicaid eligibility only to those under $23 \% \mathrm{FPL} ;{ }^{24}$ the state thus experienced considerable increase in eligibility in January 2014 when it expanded to 133\% FPL. Similarly, in Iowa, childless adults with income below 200\% FPL were eligible for public health insurance through the IowaCare program since 2000, but IowaCare provided limited services in a limited network, and so the state effectively underwent substantial expansion in coverage in $2014 .{ }^{25}$ Following the Medicaid expansion literature, we therefore use a single indicator to indicate Medicaid expansion to low-income childless adults in 2014.

There are many classifications of rurality, such as the USDA Economic Research Service (ERS) rural-urban continuum codes. The ACS does not include rural-urban continuum codes but does include PUMA of residence for each respondent. A PUMA is a statistical geographic area that is nested within a state, geographically contiguous, built on census tract and county lines, and contains at least 100,000 people. We identified rural PUMAs based on population density, which we obtained from the US Census Bureau's population data. If the population density of a PUMA (based on population and land area) was less than 500 persons per square mile, it was classified as rural. This definition is consistent with the US Census Bureau's definition of urban as "territory, population, and housing units located within an urbanized area (UA) or an urban cluster (UC), which has: a population density of at least 1,000 people per square mile; and 
surrounding census blocks with an overall density of at least 500 people per square mile." Correspondingly, "rural" is defined as "all territory, population and housing units located outside of UAs and UCs." This definition of rural has been recognized by previous researchers ${ }^{26}$ and by the US Health Resources and Services Administration. ${ }^{27}$

Because of a change in PUMA classification that occurred beginning with ACS 2012, we performed the population density calculations separately for the year prior to 2012 . For the year 2011, the PUMA boundaries were based on Census 2000, and so we used Census 2000 PUMA population and land area data to classify PUMAs as rural or urban. For the years 2012-2015, the Census Bureau changed the PUMA boundaries based on the 2010 Census data, so we used Census 2010 PUMA population and land area to classify PUMAs as rural or urban. For the purposes of our analysis, we simply need to identify individual respondents as rural or urban using their PUMA of residence and year of response. We do not use any PUMA-specific characteristics other than rurality (which we calculate separately for each PUMA-year), and so the change in PUMA classification does not interfere with our identification.

The primary analysis was restricted to low-income non-disabled childless adults aged 1964 (henceforth referred to as "childless adults"), as this is the population expected to benefit most directly from the Medicaid expansion. All the expansion states had operational Medicaid programs before the ACA, but eligibility was largely limited to low-income parents, children, pregnant women, and disabled people. Among expansion states, parents' eligibility increased from a median $100 \%$ FPL to $133 \%$ FPL whereas childless adults' eligibility increased from a median $0 \%$ to $133 \% .{ }^{28}$ Therefore, we selected from the ACS childless adults who were aged 1964, below $100 \%$ of the FPL, not disabled (as measured by the ACS “disability recode" variable), and not covered by VA Health Care or Indian Health Service. The purpose of the last restriction 
was to remove populations who always had access to forms of public insurance and were consequently expected to be unaffected by the Medicaid expansion.

The Medicaid expansion was in fact available for adults up to $133 \%$ FPL, but we limited our sample to only those below 100\% FPL because adults with income 100-400\% FPL in nonexpansion states became eligible for marketplace subsidies in 2014 that significantly reduced their premium burden. For example, before January 2014, a single adult at 133\% FPL would have paid about $\$ 3,000$ annual premium for a silver plan, but would pay only about $\$ 300$ annual premium after January 2014. This means that people 100-133\% FPL in non-expansion states effectively received an insurance expansion, and so including this population would contaminate our control group.

To identify individuals below 100\% FPL, we first estimated the individual's modified adjusted gross income (MAGI), which is the measure used to determine eligibility for public insurance programs. Following Heim \& $\operatorname{Lin},{ }^{29}$ we used information on relationships between respondents to identify family units, determine the number of dependents, and calculate total family income net of supplemental security income and public assistance income. We then used annual poverty guidelines published by the US Department of Health and Human Services to obtain each individual's FPL ratio (individual's family MAGI divided by the poverty level for the individual's state/family size/year).

To measure insurance coverage, we created binary outcomes variables from the ACS that indicated (1) having any health insurance, (2) having Medicaid coverage, (3) having Medicare coverage, (4) having employer sponsored insurance (including Tricare), and (5) having individual purchased private insurance coverage. 
Additional covariates measured from the ACS included age, male, and race. Age is a continuous variable measuring the individual's reported age in years. Male is a binary variable equal to 1 if the individual was male and 0 otherwise. Race is a vector of binary variables indicating the individual's reported race (White alone, Black or African American alone, American Indian alone, Alaska Native alone, American Indian and Alaska Native, Asian alone, Native Hawaiian and other Pacific Islander alone, some other race alone, or two or more races).

Design and statistical analyses. Our statistical analysis followed a difference-indifferences (DD) regression method where we compared outcomes for childless adults residing in expansion versus non-expansion states, after and before 2014. To measure the differential impact for rural populations, we included an additional interaction term for rural. For each of our outcome variables, we estimated the following OLS regression:

$$
Y_{\text {igst }}=\alpha+\gamma\left(\text { Expansion }_{s} \text { Post }_{t}\right)+\beta\left(\text { Expansion }_{s} * \text { Post }_{t} * \text { Rural }_{g}\right)+\eta \boldsymbol{X}_{\text {igst }}+\delta \text { State }_{s}+\text { YTime }_{t}+\varepsilon
$$

where $Y_{\text {igst }}$ represents a binary insurance coverage outcome for individual $i$ living in state $s$ in rural category $g$ in year $t$. Expansion is a binary variable equal to 1 if the individual lives in an expansion state, and equals 0 if the respondent lives in a non-expansion state. Post is a binary variable equal to 1 if the time period is after the policy implementation (i.e. 2014-15) and equals 0 if the time period is prior to the 2014 expansions (i.e., 2011-13). Rural is a binary variable equal to 1 if the individual lives in a rural PUMA (i.e. population density less than 500 persons per square mile) and 0 otherwise. $X$ is the vector of covariates: age, gender, and race. State is a vector of state fixed effects, and Time is a vector of year-fixed effects. Standard errors are robust and clustered by state. The coefficient $\gamma$ is an estimate of the causal impact of Medicaid expansion on the probability of having insurance, and the coefficient $\beta$ estimates the additional impact for those living in rural regions. 
Falsification tests and sensitivity analyses. The validity of the DD model relies on the parallel trends assumption: that in the absence of the Medicaid expansion, outcomes in the expansion states would have followed the same trend as those in the non-expansion states. We assessed parallel trends by estimating regressions using only data prior to the enactment of the law in 2014. We kept the same outcome variables on the left-hand side and the same control variables on the right-hand side, but our key independent variable now was an interaction between the linear time trend and the expansion group dummy instead of the usual DD variables.

To further assess the validity of our model, we conducted falsification tests by estimating our regression model using adults over age 65 and high-income adults above $400 \%$ of the FPL, i.e. populations who were unaffected by the 2014 Medicaid expansion. If we find significant effects of the expansions on insurance rates for either of these populations, it would imply that the model may be biased.

In later sensitivity analyses, we included marital status, unemployment status, years of education, and family income as additional covariates. We also estimated models that exclude states that expanded during the middle of the year (MI, NH, IN, and AK) and the states that had the strongest Medicaid expansions prior to 2014 and thus experienced only "mild" expansion in 2014 (CT, DC, DE, HI, MN, NY, and VT). We also estimated models that use an alternate definition of rurality, have equal pre- and post-time durations, use only expansion states, include those below 133\% FPL in the sample, include all nonelderly adults, and use pseudo outcomes to assess whether there were changing economic circumstances between expansion and nonexpansion states.

\section{Results}


A summary of the demographic characteristics and insurance rates of the childless adults sample is provided in Table 1. Table 1 presents the pre-expansion means for age and schooling and proportions for all other variables, separately for rural and urban populations. For most demographic characteristics, rural childless adults were significantly different from urban childless adults, but the magnitudes of the difference are small compared to the baseline values. For example, the rural population was on average 0.166 years older than the urban population, a difference of only about $0.5 \%$. The differences in race, though, were larger in magnitude. For example, $75 \%$ of the rural population was White versus only $57 \%$ of the urban population; this represents a difference of about $31 \%$. Similarly, the rural population was less likely to be Black (6.2 percentage point or $28 \%$ difference), less likely to be Asian (6.5 percentage point or $70 \%$ difference), and less likely to be Hispanic (12.3 percentage point or 49\% difference). Previous studies show that post-ACA public insurance rates increased more among the Black and Hispanic populations than the White population, ${ }^{22}$ which suggests that rural populations (which are more heavily populated by Whites) may actually experience a smaller increase in probability of having insurance relative to urban areas.

Table 2 presents the primary findings of the DD analysis, employing sample weights and adjusting for covariates. Panel 1 of Table 2 displays results for childless adults, our primary population of interest, and Panel 2 displays results for all low-income adults (including parents). For both populations, the "Post X Expansion" term was positive and statistically significant for "any insurance" $(\mathrm{p}<.01)$ and "Medicaid" $(\mathrm{p}<.001)$, suggesting that Medicaid expansion resulted in a significant increase in the probability of having any insurance and having Medicaid for urban and rural low-income populations pooled. Specifically, for "any insurance" the increase was 6.5 percentage points (or $12 \%$ from pre-expansion level) for childless adults and 4.4 
percentage points (or 8\%) for all adults; for "Medicaid" the increase was 8.7 percentage points (or 68\%) for childless adults and 6.8 percentage points (or $40 \%$ ) for all adults. As expected, the magnitude of the changes were smaller for the sample that includes parents because in most states parents already had considerable eligibility for public insurance programs even before the ACA.

For both populations, the "Post X Expansion" term was negative and statistically significant for "individual purchased" insurance $(\mathrm{p}<.01)$, suggesting that Medicaid expansion reduced the probability of having individual purchased insurance for both urban and rural lowincome populations. Specifically, the decrease was 1.3 percentage points (or $13 \%$ decline from pre-expansion level) for childless adults and 1.6 percentage points (or 18\% decline) for all adults. The Medicaid expansion did not result in significant changes in the probability of having Medicare or employer-sponsored insurance among either of these low-income populations.

The "Post X Expansion X Rural" term was positive and statistically significant for the Medicaid outcome $(\beta=0.019, \mathrm{p}<.05)$, suggesting that rural childless adults, compared to urban childless adults, experienced a 1.9 percentage point larger increase in the probability of having Medicaid as a result of the expansion. The "Post X Expansion X Rural" term was negative and statistically significant for the individual purchased insurance outcome $(\beta=-0.015, \mathrm{p}<.01)$, suggesting that rural childless adults experienced a 1.5 percentage point larger decline in the probability of having individual purchased insurance. The overall probability of having "any insurance," "employer-sponsored insurance," or "Medicare" was not significantly different for rural and urban populations.

Table 3 shows the results of a set of falsification tests and sensitivity analyses, designed to test the specificity of the changes to the targeted Medicaid population. For the falsification 
tests displayed in Panels 1 and 2, we examined two alternative populations, including adults over age 65 and high income adults. As expected, there were few significant changes in these populations associated with Medicaid expansion, and even the significant changes observed were modest compared to pre-expansion means for this population. Panel 3 of Table 3 shows results of pre-expansion parallel trends tests. As expected, no significant rural-urban differences preexpansion were observed among childless adults, so we cannot reject the null hypothesis of equal trends between expansion and non-expansion states before 2014. This provides reassuring evidence that the parallel trends assumption of the DD study design is satisfied for our analysis.

Panel 4 of Table 3 displays results from a sensitivity test that includes a richer set of control variables (including years schooling, marital status, and unemployment) for our original sample of low-income childless adults. As expected, the substantive results remain largely the same. Panel 5 of Table 3 uses only the "clean" expansion and non-expansion states, omitting states that offered some eligibility to childless adults before 2014 or expanded mid-year. As expected, the magnitudes of the coefficients are larger but the direction of the results remains the same.

Results from the remaining sensitivity tests listed at the end of the Methods section are available in Appendix Tables 1-2. Overall, we find that our results are not sensitive to any of these specification changes.

\section{Discussion}

In conclusion, we observed that the ACA Medicaid expansion significantly increased the probability of having "any insurance" for rural and urban childless adults pooled, but it did not result in differential changes for rural populations versus urban populations for overall insurance. 
For Medicaid coverage specifically, however, the expansion helped to bridge the gap in Medicaid insurance rates between rural and urban childless adults, though some of these gains were offset by reductions in individual purchased insurance among rural populations. This suggests that there may have been a shift from individual purchased private insurance to Medicaid among the rural population; implications for personal expenditures, access to care and utilization can be a topic for future work.

These results are consistent with a report by Karpman et al. ${ }^{12}$ However, this study did not examine whether differential changes for rural and urban populations were statistically meaningful, and ours is the first study to observe an increase in Medicaid coverage that was significantly higher in rural populations than in urban. We also conducted an analysis over a longer time frame and added statistical controls for confounds. This is important preliminary evidence that the Medicaid expansion has been of particular benefit for rural populations in those states where it has occurred.

Reasons for the differential rural benefit may relate to the conditions present in rural and urban areas prior to expansion. These prior conditions indicate greater unmet need in rural areas that could be uniquely and partially met by the expansion. Unmet need is evidenced by lower rates of insurance in rural areas and greater financial burdens from out of pocket costs. To the extent that private alternatives through HIMs were less accessible in rural areas, the Medicaid expansion may have provided a unique mechanism for rural populations to gain access to health insurance. Furthermore, it may have allowed rural people to discontinue individually-purchased insurance in place of Medicaid.

A recent analysis by Kaufman et al. considered the effects of the Medicaid expansion on rural and urban hospitals. ${ }^{30}$ Similar to ours, this study found that expansion increased medical 
utilization in rural areas in expansion states but did not significantly reduce uncompensated care costs or increase operating margins for rural hospitals. The authors suggest that planned reductions in Medicaid disproportionate-share hospital supplemental payments may place greater pressures on rural hospitals that still rely heavily on Medicaid payments. The impacts of the Medicaid expansion on rural populations, communities and providers will be complex and include health care access, cost, and outcome considerations which will require ongoing evaluation.

A study by Han et al. ${ }^{31}$ did not examine the ACA but showed pre-ACA that persons in states that were not expanding Medicaid were more likely to be Black or to live in rural areas compared to expanding states. That is, states that are not expanding have larger African American and rural populations; in general, these populations may be vulnerable to greater health disparities. ${ }^{22}$ Non-expanding states also had pre-ACA indications of poorer access to care and poorer health status among low income people. ${ }^{31}$ As noted earlier in the current paper, it has also been observed that rural populations take less advantage of private coverage through HIMs. ${ }^{13,14}$ This combination places low income persons who live in rural areas in non-expanding states at the greatest risk of not experiencing benefits under the ACA.

Strengths of our study include the application of a DD analysis to identify the causal impact of Medicaid expansion while controlling for time-invariant (through year-fixed effects) and state-invariant (through state-fixed effects) factors. We also controlled statistically for a set of potential confounds, and we employed a large and nationally representative sample that allowed us to identify changes in types of health insurance coverage over time. Furthermore, we conducted a series of falsification tests and sensitivity analyses that confirmed the robustness of 
our findings. The falsification tests and sensitivity analyses were largely consistent with expectations.

A number of study limitations should also be noted. Most states that adopted the Medicaid expansion did so beginning in 2014, but several late adopters began the expansion at later dates. ${ }^{1}$ This may reduce our ability to detect expansion effects and may render our findings more conservative. Secondly, we are measuring only short-term effects as we have only two years of post-expansion data. Thirdly, our definition of rural was based on an accepted definition used by the US Census Bureau, but results may be influenced by the use of alternative definitions such as county-based rural-urban influence codes. Our use of PUMA identifiers is justified in the interest of providing timely results; future research with other specifications (such as provided in the restricted-access data center version of Medical Expenditure Panel Survey which provides rural/urban identifiers but has a much smaller sample size than the ACS) could examine consequences of rural/urban differences in the impact of the Medicaid expansions. Finally, results are potentially limited by the self-report nature of the data and by the survey representativeness; we employed survey weights to account for survey nonresponse by key demographic variables.

Future research can assess whether our observed shift in rural areas from individual purchased insurance to Medicaid resulted in improved affordability and health status for rural populations. It will also be important to monitor health care access and health status among rural populations in non-expansion states to detect any potential health disparities that emerge over time among persons who cannot access the benefits of the ACA Medicaid expansion. 


\section{References}

1. Status of state action on the Medicaid expansion decision. Henry J. Kaiser Family Foundation, 2016. (Accessed 02-22-16, at http://kff.org/health-reform/state-indicator/state-activity-around-expandingmedicaid-under-the-affordable-care-act/.)

2. Sommers BD, Gunja MZ, Finegold K, Musco T. Changes in self-reported insurance coverage, access to Care, and health under the Affordable Care Act. JAMA 2015;314:366-74.

3. Frean M, Gruber J, Sommers BD. Premium subsidies, the Mandate, and Medicaid expansion: coverage effects of the Affordable Care Act. Cambridge, MA: National Bureau of Economic Research, Working Paper No. 22213; 2016.

4. Courtemanche C, Marton J, Ukert B, Yelowitz A, Zapata D. Impacts of the Affordable Care Act on health insurance coverage in Medicaid expansion and non-expansion states. Cambridge, MA: National Bureau of Economic Research, Working Paper No. 22182; 2016.

5. Simon K, Soni A, Cawley J. The impact of health insurance on preventive care and health behaviors: evidence from the 2014 ACA Medicaid expansions. Cambridge, MA: National Bureau of Economic Research, Working Paper No. 22265.; 2016.

6. Wherry LR, Miller S. Early coverage, access, utilization, and health effects associated with the Affordable Care Act Medicaid expansions: a quasi-experimental study. Ann Intern Med 2016;164:795803.

7. Sommers BD, Blendon RJ, Orav EJ. Both the 'private option' and traditional Medicaid expansions improved access to care for low-income adults. Health Affairs 2016;35:96-105.

8. Bennett KJ, Dismuke CE. Families at financial risk due to high ratio of out-of-pocket health care expenditures to total income. J Health Care Poor Underserved 2010;21:691-703.

9. Smith JC, Medalia C. Health Insurance in the United States: 2013. Washington DC: Current Population Reports, United States Census Bureau; 2014:60-250.

10. Ziller EC, Coburn AF, Anderson NJ, Loux SL. Uninsured rural families. J Rural Health 2008;24:1-11. 
11. Coburn AF, Lundblad JP, MacKinney AC, McBride TD, Mueller KJ. The Patient Protection and Affordable Care Act of 2010: impacts on rural people, places, and providers: a first look. Iowa City, IA: Rural Policy Research Institute; 2010.

12. Karpman M, Zuckerman S, Kenney GM, Odu Y. Quicktake: Substantial gains in health insurance coverage occurring for adults in both rural and urban areas. Washington, DC2015 April 16, 2015.

13. Drake C, Abraham JM, McCullough JS. Rural enrollment in the Federally Facilitated Marketplace. J Rural Health 2016;32:332-9.

14. Barker AR, McBride TD, Kemper LM, Mueller KJ. Rural enrollment in Health Insurance Marketplaces, by state. Rural Policy Brief 2015;11:1-4.

15. Look KA, Kim NH, Arora P. Effects of the Affordable Care Act's dependent coverage mandate on private health insurance coverage in urban and rural areas. J Rural Health 2016; epub ahead of print. 16. Sommers BD, Chua KP, Kenney GM, Long SK, McMorrow S. California's early coverage expansion under the Affordable Care Act: a county-level analysis. Health Serv Res 2016;51:825-45. 17. Benitez JA, Creel L, Jennings J. Kentucky's Medicaid expansion showing early promise on coverage and access to care. Health Affairs 2016;35:528-34.

18. Burns ME, Dague L, DeLeire T, et al. The effects of expanding public insurance to rural lowincome childless adults. Health Serv Res 2014;49 Suppl 2:2173-87.

19. Long SK, Dahlen H. Expanding coverage to low-income childless adults in Massachusetts: implications for national health reform. Health Serv Res 2014;49 Suppl 2:2129-46.

20. American Community Survey (ACS). 2015. (Accessed 08-17-16, at http://www.census.gov/programs-surveys/acs/about.html.)

21. Public Use Microdata Areas. 2015. (Accessed 08-17-16, at https://www.census.gov/geo/reference/puma.html.)

22. Buchmueller TC, Levinson ZM, Levy HG, Wolfe BL. Effect of the Affordable Care Act on racial and ethnic disparities in health insurance coverage. Am J Public Health 2016;106:1416-21. 
23. Gates A, Rudowitz R. Wisconsin's BadgerCare Program and the ACA. Manlo Park, CA: Kaiser Family Foundation; 2014.

24. Sommers BD, Buchmueller T, Decker SL, Carey C, Kronick R. The Affordable Care Act has led to significant gains in health insurance and access to care for young adults. Health Aff (Millwood) 2013;32:165-74.

25. Damiano P, Bentler SE, Momany ET, Park KH, Robinson E. Evaluation of the IowaCare program: information about the medical home expansion. Iowa City, IA, University of Iowa Public Policy Center; 2013.

26. Hall SA, Kaufman JS, Ricketts TC. Defining urban and rural areas in U.S. epidemiologic studies. J Urban Health 2006;83:162-75.

27. How is rural defined? Health Resources and Services Administration US Department of Health and Human Services 2016. (Accessed 08-17-16, at http://www.hrsa.gov/healthit/toolbox/RuralHealthITtoolbox/Introduction/defined.html.) 28. Trends in Medicaid and CHIP eligibility over time. Kaiser Family Foundation, 2016. (Accessed 10-25-16, at http://kff.org/report-section/trends-in-medicaid-and-chip-eligibility-over-time-section-3eligibility-trends-by-medicaid-expansion-status-2016-update/.)

29. Heim BT, Lin L. Does health reform lead to an increase in early retirement? Evidence from Massachusetts. ILR Review 2016; epub ahead of print.

30. Kaufman BG, Reiter KL, Pink GH, Holmes GM. Medicaid Expansion affects rural and urban hospitals differently. Health Aff (Millwood) 2016;35:1665-72.

31. Han X, Nguyen BT, Drope J, Jemal A. Health-related outcomes among the poor: Medicaid expansion vs. non-expansion states. PLoS One 2015;10:e0144429. 


\section{Table 1. Unadjusted Means for Rural and Urban Areas, Before Expansion}

\begin{tabular}{lccc}
\hline & Urban $(1)$ & Rural $(2)$ & $\begin{array}{c}\text { Pre-Expansion Rural- } \\
\text { Urban Difference }(5)\end{array}$ \\
\hline Age & 31.35 & 31.52 & $0.166^{* * *}$ \\
Years Schooling & 12.50 & 12.32 & $-0.180^{* * *}$ \\
Unemployed & 0.185 & 0.160 & $-0.026^{* * *}$ \\
Married & 0.099 & 0.107 & $0.007^{* * *}$ \\
Male & 0.523 & 0.556 & $0.033^{* * *}$ \\
Race & & & \\
White & 0.571 & 0.750 & $0.178^{* * *}$ \\
Black & 0.218 & 0.156 & $-0.062^{* * *}$ \\
Native American & 0.005 & 0.009 & $0.004^{* * *}$ \\
Asian & 0.093 & 0.028 & $-0.065^{* * *}$ \\
Other & 0.081 & 0.033 & $-0.048^{* * *}$ \\
Multi-racial & 0.033 & 0.025 & $-0.008^{* * *}$ \\
Hispanic & 0.252 & 0.129 & $-0.123^{* * *}$ \\
Any health insurance & 0.596 & 0.574 & $-0.022^{* * *}$ \\
Medicaid & 0.160 & 0.147 & $-0.013^{* * *}$ \\
Medicare & 0.024 & 0.028 & $0.005^{* * *}$ \\
Employer \\
sponsored
\end{tabular}

Notes: Authors' calculations based on ACS 2011-13. Sample is restricted to non-disabled childless adults who are below age 65, below 100\% FPL, and not covered by VA Health Care or Indian Health Service. All variables are binary except for Age and Years Schooling, which are continuous. Calculations account for ACS sample weights. ${ }^{*}$ Difference significant at $5 \%$ level, ${ }^{* *}$ Difference significant at $1 \%$ level, ${ }^{* * *}$ Difference significant at $0.1 \%$ level. 
Table 2. Estimates for the Impact of Medicaid Expansion

\begin{tabular}{lccccc}
\hline & $\begin{array}{c}\text { Any } \\
\text { insurance }\end{array}$ & Medicaid & Medicare & $\begin{array}{c}\text { Employer } \\
\text { sponsored }\end{array}$ & $\begin{array}{c}\text { Individual } \\
\text { purchased }\end{array}$ \\
\hline Panel 1: Low-income childless adults & $(N=1,512,497)$ & & & \\
Post X Expansion X & -0.006 & $0.019^{*}$ & 0.003 & -0.012 & $-0.015^{* * *}$ \\
Rural & $(0.009)$ & $(0.008)$ & $(0.002)$ & $(0.008)$ & $(0.004)$ \\
Post X Expansion & $0.065^{* * *}$ & $0.087^{* * *}$ & -0.000 & -0.006 & $-0.013^{* *}$ \\
& $(0.017)$ & $(0.013)$ & $(0.001)$ & $(0.006)$ & $(0.005)$ \\
Pre-expansion mean & 0.530 & 0.128 & 0.050 & 0.307 & 0.101 \\
\hline Panel 2: Low-income adults $(N=1,739,445)$ & & & \\
Post X Expansion X & 0.007 & $0.028^{* *}$ & $0.003^{* *}$ & -0.006 & $-0.011^{* *}$ \\
Rural & $(0.008)$ & $(0.009)$ & $(0.001)$ & $(0.009)$ & $(0.004)$ \\
Post X Expansion & $0.044^{* *}$ & $0.068^{* * *}$ & -0.001 & -0.010 & $-0.016^{* *}$ \\
Pre-expansion mean & $(0.015)$ & $(0.011)$ & $(0.001)$ & $(0.005)$ & $(0.005)$ \\
\hline
\end{tabular}

Notes: Authors estimates based on ACS 2011-15. In panel 1, sample is restricted to non-disabled childless adults, age 19-64 and below 100\% FPL. In panel 2, sample is restricted to non-disabled adults (both childless and parents), age 19-64 and below 100\% FPL. State-clustered standard errors in parentheses. All regressions control for age, gender, race, state-fixed effects, and year-fixed effects. Regressions account for ACS sample weights. Pre-expansion mean is for non-expansion states only. ${ }^{*} p<0.05,{ }^{* *} p<0.01,{ }^{* * *} p<0.001$ 
Table 3. Falsification Tests and Sensitivity Analyses

\begin{tabular}{|c|c|c|c|c|c|}
\hline & $\begin{array}{c}\text { Any } \\
\text { insurance }\end{array}$ & Medicaid & Medicare & $\begin{array}{l}\text { Employer } \\
\text { sponsored }\end{array}$ & $\begin{array}{l}\text { Individual } \\
\text { purchased }\end{array}$ \\
\hline \multicolumn{6}{|c|}{ FALSIFICATION TESTS } \\
\hline \multicolumn{6}{|c|}{ Panel 1: Over age $65(N=2,555,215)$} \\
\hline $\begin{array}{l}\text { Post X Expansion X } \\
\text { Rural }\end{array}$ & $\begin{array}{c}0.001 \\
(0.001)\end{array}$ & $\begin{array}{l}-0.009 \\
(0.005)\end{array}$ & $\begin{array}{l}0.008^{* * *} \\
(0.001)\end{array}$ & $\begin{array}{l}-0.005 \\
(0.008)\end{array}$ & $\begin{array}{l}0.033^{* * *} \\
(0.007)\end{array}$ \\
\hline Post X Expansion & $\begin{array}{c}0.000 \\
(0.000)\end{array}$ & $\begin{array}{c}0.007 \\
(0.004)\end{array}$ & $\begin{array}{l}-0.003^{* * *} \\
(0.001)\end{array}$ & $\begin{array}{c}0.002 \\
(0.004)\end{array}$ & $\begin{array}{l}-0.012^{* * *} \\
(0.003)\end{array}$ \\
\hline Pre-expansion mean & 0.991 & 0.153 & 0.975 & 0.371 & 0.343 \\
\hline \multicolumn{6}{|c|}{ Panel 2: High-income, $>400 \%$ FPL $(N=3,144,298)$} \\
\hline $\begin{array}{l}\text { Post X Expansion X } \\
\text { Rural }\end{array}$ & $\begin{array}{l}-0.005^{* *} \\
(0.002)\end{array}$ & $\begin{array}{c}\text { N/A; } \\
\text { Medicaid }\end{array}$ & $\begin{array}{l}0.001^{* * *} \\
(0.000)\end{array}$ & $\begin{array}{l}-0.005 \\
(0.003)\end{array}$ & $\begin{array}{c}0.002 \\
(0.003)\end{array}$ \\
\hline Post X Expansion & $\begin{array}{c}0.001 \\
(0.002)\end{array}$ & $\begin{array}{l}\text { unavailable } \\
\text { in this }\end{array}$ & $\begin{array}{c}0.000 \\
(0.000)\end{array}$ & $\begin{array}{c}0.001 \\
(0.002)\end{array}$ & $\begin{array}{l}-0.004 \\
(0.002)\end{array}$ \\
\hline Pre-expansion mean & 0.946 & income range & 0.006 & 0.872 & 0.104 \\
\hline \multicolumn{6}{|c|}{ Panel 3: Pretrends test $(N=788,612)$} \\
\hline $\begin{array}{l}\text { Time X Expansion X } \\
\text { Rural }\end{array}$ & $\begin{array}{l}-0.003 \\
(0.004)\end{array}$ & $\begin{array}{c}0.008 \\
(0.006)\end{array}$ & $\begin{array}{c}0.002 \\
(0.001)\end{array}$ & $\begin{array}{l}-0.007 \\
(0.005)\end{array}$ & $\begin{array}{l}-0.004 \\
(0.003)\end{array}$ \\
\hline Time X Expansion & $\begin{array}{c}0.000 \\
(0.003)\end{array}$ & $\begin{array}{l}-0.001 \\
(0.003)\end{array}$ & $\begin{array}{l}-0.001 \\
(0.001)\end{array}$ & $\begin{array}{c}0.003 \\
(0.002)\end{array}$ & $\begin{array}{l}-0.002 \\
(0.002)\end{array}$ \\
\hline
\end{tabular}

\section{SENSITIVITY ANALYSES}

Panel 4: All control variables $(N=1,299,404)$

\begin{tabular}{lccccc} 
Post X Expansion X & $-0.018^{*}$ & $0.017 *$ & 0.001 & $-0.017 *$ & $-0.019 * * *$ \\
Rural & $(0.007)$ & $(0.006)$ & $(0.001)$ & $(0.007)$ & $(0.004)$ \\
Post X Expansion & $0.060^{* * *}$ & $0.080^{* * *}$ & -0.001 & -0.007 & $-0.013^{* *}$ \\
& $(0.014)$ & $(0.014)$ & $(0.001)$ & $(0.006)$ & $(0.005)$ \\
Pre-expansion mean & 0.538 & 0.118 & 0.026 & 0.332 & 0.106 \\
\hline Panel 5: Limited set of states $(N=1,084,409)$ & & & \\
Post X Expansion X & -0.011 & $0.021^{*}$ & 0.001 & -0.017 & $-0.015^{* *}$ \\
Rural & $(0.009)$ & $(0.009)$ & $(0.001)$ & $(0.010)$ & $(0.005)$ \\
Post X Expansion & $0.071 * * *$ & $0.093^{* * *}$ & -0.000 & -0.006 & $-0.015^{* *}$ \\
& $(0.016)$ & $(0.012)$ & $(0.001)$ & $(0.006)$ & $(0.005)$ \\
Pre-expansion mean & 0.535 & 0.119 & 0.026 & 0.328 & 0.106
\end{tabular}

Notes: Authors estimates based on ACS 2011-15. In panel 1, sample is restricted to adults over age 65. In panel 2, sample is restricted to adults over $400 \%$ FPL, age 19 to 64. In panels 3-5, sample is restricted to non-disabled childless adults, age 19-64 and below 100\% FPL. Panel 3 excludes years 2014-15 (i.e. post expansion years). Panel 
1

2

3

4

5

6

7

8

9

10

11

12

13

14

15

16

17

18

19

20

21

22

23

24

25

26

27

28

29

30

31

32

33

34

35

36

37

38

39

40

41

42

43

44

45

46

47

48

49

50

51

52

53

54

55

56

57

58

59

60
5 excludes individuals residing in CT, DC, DE, HI, IN, MI, MN, NH, NY, and VT. State-clustered standard errors in parentheses. All regressions control for age, gender, race, state-fixed effects, and year-fixed effects. Regressions account for ACS sample weights. Pre-expansion mean is for non-expansion states only. ${ }^{*} p<0.05,{ }^{* *} p<0.01,{ }^{* * *} p$ $<0.001$ 
Figure 1: Trends in Insurance Rates, Rural vs. Urban Areas in Expansion and Nonexpansion States.
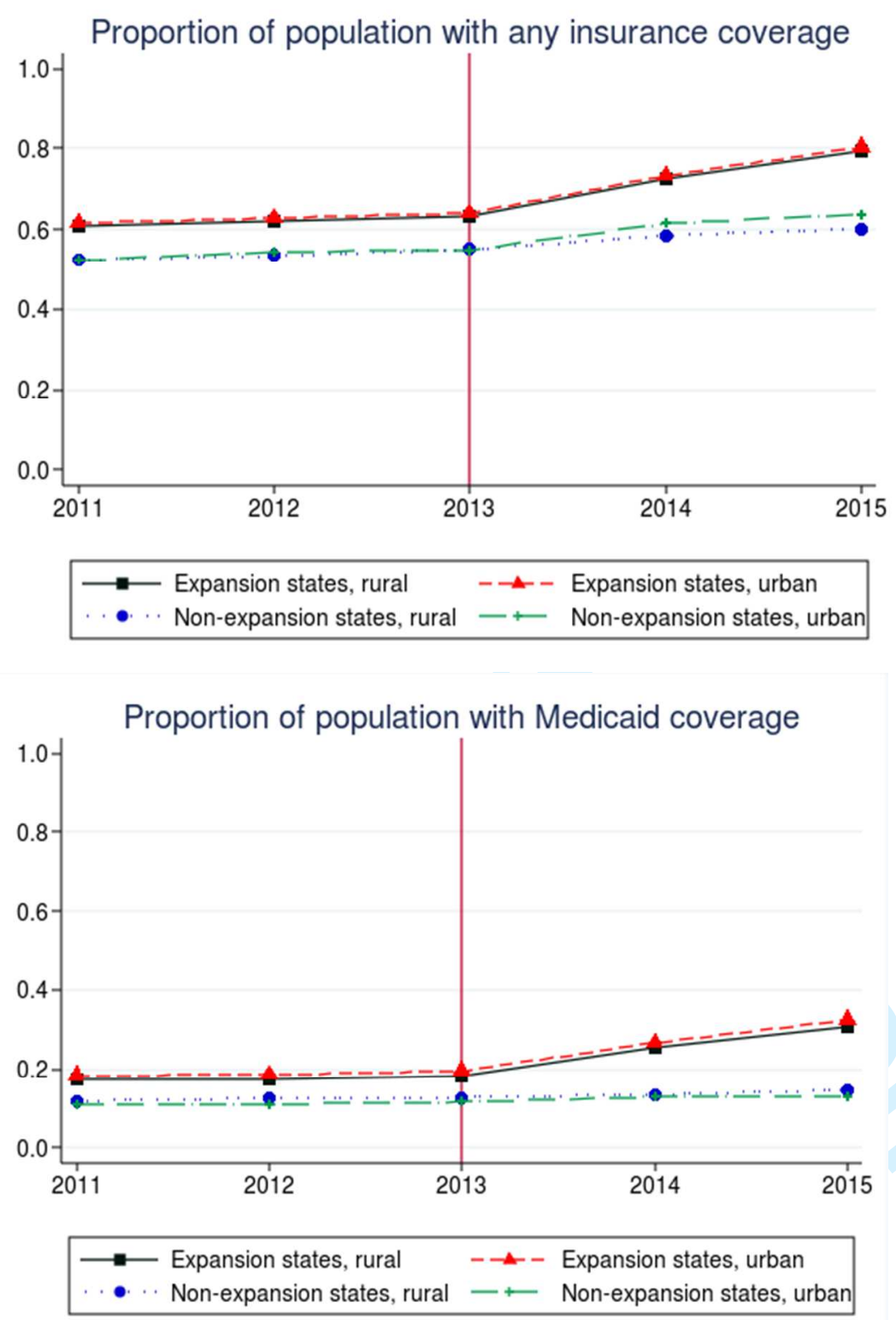

Notes: Authors' estimates based on ACS 2011-15. Sample is restricted to non-disabled childless adults, age 19-64 and below 100\% FPL. State-clustered standard errors in parentheses. Proportions include ACS sample weights. 